\title{
THE MOON
}

With Coloured Skeleton Maps of Front and Far Side of the Moon, Scale 1:6000000 by ZDENĚK KOPAL

1969, XVI + 525 pp., Dfl. 95,-

CONTENTS :

Preface

Preface to the First Edition

PART ONE/MOTION OF THE MOON AND DYNAMICS OF THE EARTHMOON SYSTEM

1. Basic Facts: Distance, Size and Mass

2. The Motion of the Moon in Space

3. Rotation of the Moon; Optical Librations

4. Motion of the Moon about its Center of Gravity; Physical Librations

5. Photometric Consequences of the Moon's Motion: Phases and Eclipses

6. Dynamics of the Earth-Moon System

Bibliographical Notes

PART TWO/INTERNAL CONSTITUTION OF THE LUNAR GLOBE Introduction

7. Hydrostatic Equilibrium and its Limitations

8. Thermal History of the Moon

9. Stress History of the Moon

10. Possible Convection in the Lunar Interior

11. Chemical Composition of the Moon

12. Exosphere of the Moon

Bibliographical Notes

PART THREE/TOPOGRAPHY OF THE MOON

Introduction

13. Global Form of the Moon and its Gravitational Field

14. Relative Coordinates on the Moon and their Determination

15. Mapping of the Moon

16. Morphology of the Lunar Surface

17. Origin of the Lunar Formations

18. Lunar Surface as an Impact Counter, and its Stratigraphy

Bibliographical Notes

PART FOUR/RADIATION OF THE MOON

Introduction

19. Photometry of Scattered Moonlight

20. Thermal Emission of the Lunar Surface

21. Electromagnetic Properties of the Lunar Surface

22. Luminescence of the Lunar Surface

23. Structure of the Lunar Surface

24. Large-Scale Features of the Lunar Surface

Bibliographical Notes

Postscript

References

Index of Names

D. REIDEL PUBLISHING COMPANY

DORDRECHT-HOLLAND 


\title{
COSMIC ELECTRODYNAMICS
}

\author{
An International Journal Devoted to Geophysical and \\ Astrophysical Plasmas
}

Editor: C. P. Sonett; Co-Editors: C.-G. Fälthammar and T. Obayashi Editorial Board: H. Alfvén, W. I. Axford, I. B. Bernstein, A. G. W. Cameron, R. L. Carovillano, P. J. Coleman, J. W. Dungey, A. Eviatar, J. W. Firor, V. L. Ginzburg, H. L. Jordan, M. Kuperus, H. Liemohn, L. Mestel, N. F. Ness, A. Nishida, T. G. Northrop, H. E. Petschek, J. H. Piddington, S. K. Runcorn, R. Z. Sagdeev, V. A. Sarabhai, F. L. Scarf, A. W. Schardt, A. Severny, J. R. Spreiter, J. A. Van Allen, M. Walt, D. Wentzel.

\section{Contents of Volume 2, No. 1, April 1971:}

V. Sarabhai and K. N. Nair / Morphology of the Geomagnetic Field Variations and a Study of the Interplanetary Magnetic Field Fluctuations in Relation to the Daily Variation of the Geomagnetic Field at Low Latitudes. - C. P. Sonett, J. D. Mihalov and J. Klozenberg/The Flux Content and Form of the Geomagnetic Tail. - A. Hruška / Model of Transverse Structure of the Geomagnetic Tail and the Reconnection Process. - F. L. Scarf and G. L. Siscoe/ The Pioneer 9 Electric Field Experiments: Part 2, Observations Between 0.75 and 1.0 AU. - S. P. Talwar / Gravitohydromagnetic Instability in Contrastreaming Plasmas. - H. Alfvén and C.-G. Fälthammar / A New Approach to the Theory of the Magnetosphere. - Aharon Eviatar, Joachim H. Joseph and Murray Dryer / Correction to the Paper 'The Effect of Interplanetary Shock Waves on the Brightness of Comets' by Aharon Eviatar, Joachim H. Joseph and Murray Drayer. - S. W. H. Cowley / The Adiabatic Flow Model of a Neutral Sheet. - R. H. Eather and R. L. Carovillano/ The Ring Current as the Source Region for Proton Auroras. - K. Schindler and André Rogister/ The Effect of Electron Anisotropy on Whistlers Leading Strong Collision-Free Shocks.

Subscription price per volume of four issues Dfl. 130,40 (US $\$ 36.55$ ) including postage. One volume is published yearly / Personal subscription price on request.

\section{REIDEL PUBLISHING COMPANY}

DORDRECHT-HOLLAND 


\title{
BOUNDARY-LAYER METEOROLOGY
}

\author{
An International Journal of Physical and Biological Processes \\ in the Atmospheric Boundary Layer
}

Editor: R. E. MunN, Toronto, Ont., Canada

Editorial Board: I. A. Balogun, P. Barry, A. Baumgartner, M. E. Berlyand, W. Böer, T. J. Chandler, R. J. Charlson, K. T. C. Cheng, A. G. Davenport, M. Estoque, H. W. Georgi, L. Hasse, U. Högström, E. Inoue, H. E. Landsberg, E. R. Lemon, H. H. Lettau, M. Miyake, A. S. Monin, D. H. Pack, H. A. Panofsky, J. R. Philit, G. D. Robinson, R. Roth, F. H. Schmidt, T. Sekiguti, V. P. Subrahmanyam, W. Swinbank, K. Takeuchi, J. Tomlain, E. Truhlar, P. Ulriksen,

Contents of Volume 1, No.4, April 1971:

Helmut Kraus / Turbulent Energy Flux and Eddy Diffusivity. - Charles R. Stearns / The Effect of Time-Variable Fluxes on Mean Wind and Temperature Profile Structure. - F. W. Dobson / The Damping of a Group of Sea Waves. - T. R. Oke and C. East / The Urban Boundary Layer in Montreal. - G. A. McBean/The Variations of the Statistics of Wind, Temperature and Humidity Fluctuations with Stability. - J. Lomas, E. Schlesinger, and A. Israeli / Leaf Temperature Measurement Techniques. - B. R. Bean et al./ Preliminary Results of Utilizing the High Resolution-FM Radar as a Boundary-Layer Probe. - P. A. Taylor / Airflow above Changes in Surface Heat Flux, Temperature and Roughness; an Extension to Include the Stable Case.

Book Review.

Index of Subjects.

Subscription price per volume of 4 issues Dfl. 144,80 (US $\$ 40.55$ ) including postage. One volume is published yearly / Personal subscription price on request.

\section{REIDEL PUBLISHING COMPANY}

\author{
DORDRECHT - HOLLAND
}




\section{SPACE OBSERVATORIES}

by Jean-Claude Pecker

translated by Janet Rountree Lesh

Astrophysics and Space Science Library, Volume 21

1970, XI + 120 pp., Dff. 35,-

Contents:

Introduction

Part I. The Raisons d'Être of Space Astronomy.

I. The Structure of the Atmospheric Layers

II. The Opaque Wall of the Atmosphere

III. Atmospheric Diffusion: Extinction and the Blue of the Sky

IV. The Inhomogeneity of the Earth's Atmosphere: Clouds and Refraction

V. The Particle Barrier

VI. The Fusion of Meteorites

Part II. A Provisional and Partial Inventory of Some of the Information to be Acquired by Space Research.

I. Beyond Diffusion

II. Beyond Turbulence

III. Beyond Ultraviolet Opacity

IV. Astronomy at Short Wavelengths

V. Beyond Infrared Opacity: Towards the Infrared by Balloon

VI. Beyond the Ionosphere: Towards Very Long Wavelengths by Eccentric Satellite

VII. A Prospective Conclusion of Limited Perspective

Conclusion

Appendix

I. Universal Physical Constants

II. The Sun

III. The Solar System

Bibliography

\section{REIDEL PUBLISHING COMPANY}

DORDRECHT-HOLLAND 


\section{PARTICLES AND FIELDS IN THE MAGNETOSPHERE}

Proceedings of a Symposium Organized by the Summer Advanced Study Institute, held at the University of California, Santa Barbara, Calif., August 4-15, 1969.

edited by B. M. McCormac

Astrophysics and Space Science Library Volume 17

1970, XI +45 pp., Dfl. 85 ,-

Contents:

Preface

I. Magnetospheric Models

II. The Bow Shock

III. Magnetospheric Particles

IV. Magnetic and Electric Fields in the Magnetosphere

V. Wave-Particles Interactions

VI. Radiation Belt Observations

VII. Acceleration and Motion of Particles

VIII. Summary

Appendix: Glossary

Index of Subjects

\section{INTERCORRELATED SATELLITE OBSERVATIONS RELATED TO SOLAR EVENTS}

Proceedings of the Third ESLAB/ESRIN Symposium held in Noordwijk, The Netherlands, September 16-19, 1969

edited by V. Manno and D. E. Page

Astrophysics and Space Science Library 19

1970, XVI + 619 pp., Dfl. 115,-

Contents:

Foreword.

List of Participants.

Introduction.

1. Summary Lecture.

2. Solar Particles and Electromagnetic Radiation.

3. Solar Wind Variations During and After Solar Events.

4. Bow Shock Variations Following Solar Events.

5. The Magnetosphere During and After Solar Events.

5a. The Magnetotail.

6. Some Ionospheric Effects Following Solar Events.

7. Satellite and Rocket Results for the February 25, 1969 Events.

8. Lecture in Conclusion.

Index of Names.

\section{REIDEL PUBLISHING COMPANY}




\title{
STRUCTURE AND EVOLUTION OF THE GALAXY
}

\author{
Proceedings of a Nato Advanced Study Institute held in Athens, \\ September 8-19, 1969
}

\author{
Edited by L. N. MAVRIDIS \\ Astrophysics and Space Science Library Volume 22 \\ 1971, VII +312 pp., Dfl. 70,-
}

This book gives a comprehensive summary of our knowledge concerning the structure and evolution of the Milky Way system. New facts like the observational evidence concerning the explosive events in the nuclei of the galaxies and the distribution of the X-Ray sources in the Milky Way, the recent theoretical work concerning neutrino stars as presented in it.

The study of the structure and evolution of the Milky Way is one of the most attractive problems of modern astronomy. Therefore, very rapid progress has been made in this field during the last years. The discovery and subsequent study of the spiral structure of the Galaxy, both with optical and radioastronomical methods, has opened wide new possibilities in the study of the structure of our stellar system. Similarly, the development of the theory of stellar evolution has made possible a more thorough study of the distribution of the stars of different ages in this system. Finally the recent discovery of explosive events in the nuclei of the extragalactic nebulae allows a much better understanding of some aspects of the evolution of the Milky Way system. The book contains the lectures given by seventeen distinguished specialists in the field during the Advanced Study Institute Conference on the Structure and Evolution of the Galaxy, held under the auspices of the Science Committee, North Atlantic Treaty Organization in Lagonissi, Greece, between September 8-19, 1969. A wide variety of subjects were covered by these lectures.

\section{Contents:}

Preface

H. Kienle / Historical Development of Our Ideas Concerning the Structure of the Galaxy

W. Fricke / Systems and Catalogues of Proper Motions

M. Golay / Photometry and Photometric Systems

H. Elsässer / Interstellar Dust

Th. Schmidt-Kaler / Space Distribution and State of Motion of the Early-Type Stars, Open Clusters, Associations, and Stellar Rings

L. N. Mavridis / Space Distribution of the Late-Type Stars

F. J. Kerr / Surveys of Radio Emission from the Galaxy

F. J. Kerr / Space Distribution and State of Motion of the Interstellar Matter as Revealed from Radio-Astronomical Observations

L. Gratton / X-Ray Sources in the Milky Way

R. Woolley / Motions of the Nearby Stars

G. Contopoulos / Recent Developments in Galactic Dynamics

P. Ledoux / Prestellar Evolution

A. G. W. Cameron / Stellar Revolution

P. Bouvier / Evolution of Stellar Clusters and Associations

E. M. Burbidge / The Evolution of Spiral Structure

G. Burbidge / The Evolution of the Galaxy as a Whole

A. Blaauw / Summary and Desiderata

Index of Names

Index of Subjects

\section{REIDEL PUBLISHING COMPANY}

DORDRECHT-HOLLAND 


\title{
SPACE SCIENCE REVIEWS
}

\author{
Editor-in-Chief: C. DE JAGER (Utrecht)
}

Editorial Board: S.-I. Akasofu, W. J. G. Beynon, J.-E. Blamont, R. L. F. Boyd, L. Broglio, M. Calvin, R. R. Daniel, H. Friedman, L. Goldberg, W. N. Hess, A. R. Hibbs, H. C. van de Hulst, G. H. Ludwig, R. Lüst, G. J. F. MacDonald, H. S. W. Massey, B. M. McCormac, A. P. Mitra, J. E. Naugle, H. E. Newell, M. Nicolet, T. Obayashi, B. J. O'Brien, B. Peters, Sir R. Peters, M. A. Pomerantz, R. W. Porter, E. Rechtin, J. G. Roederer, B. Rossi, L. I. Sedov, J. A. Van Allen, F. L. Whipple, J. R. Winckler.

\section{Contents of Volume 11, No. 6, March 1971:}

A. Vallance Jones / Auroral Spectroscopy. - Carl Sagan / The Solar System beyond Mars: An Exobiological Survey.

Contents of Volume 12, No. 1, May 1971:

V. Canuto and H. Y. Chiu / Intense Magnetic Fields in Astrophysics. - Martin A. Pomerantz and Shakti P. Duggal / The Cosmic Ray Solar Diurnal Anisotropy.

Book Reviews.

Subscription price per volume of 6 issues Df. 178,10 (US $\$ 49.90$ ) including postage. One and a half volumes are published yearly / Personal subscription price on request.

\section{REIDEL PUBLISHING COMPANY}

$$
\text { DORDRECHT-HOLLAND }
$$




\title{
SOLAR PHYSICS
}

\author{
A Journal for Solar Research and the Study of Solar \\ Terrestrial Physics
}

Editors: C. DE JAGER (Utrecht) - Z. ŠvestKa (Prague)

Contents of Volume 17, No. 1, March 1971:

\begin{abstract}
Albrecht Unsöld / In Memoriam M. G. J. Minnaert. - Franz-Ludwig Deubner / Some Properties of Velocity Fields in the Solar Photosphere. III: Oscillatory and Supergranular Motions as a Function of Height. - G. Stellmacher and E. Wiehr / Magnetically Non Split Lines in Penumbrae. - H. Schleicher and E. H. Schröter / On Equivalent Widths in a Penumbral Spectrum (A Test of the Moe-Maltby Model). S. B. Pikel'ner / Origin of Quiescent Prominences. - Tadashi Hirayama / Spectral Analysis of Four Quiescent Prominences Observed at the Peruvian Eclipse. - Richard G. Teske / Soft Solar X-Rays and Solar Activity. III: Loop Prominences with Soft X-Ray Emission. - B. Caccin et al. / Spectropolarimetric Analysis of the Solar Corona during the 12 November, 1966 Total Eclipse. - M. Blaha / Theoretical Intensities of FexIV in the Solar EUV Spectrum. - Serge Koutchmy and Kenneth H. Schatten / Observations and Discussions Concerning 'High' Polarization Features in the Solar Corona. - L. L. Baselyan and V. G. Sinitsin / Scattering of Radiowaves from Cosmic Sources in the Solar Corona. - J. H. Parkinson and K. A. Pounds / X-Ray Observations of Solar Active Regions from OSO-5. - P. R. Sengupta / A Method of Calculating 0-20 $\AA$ Solar X-Ray Flux and its Spectral Distribution Using $9.1 \mathrm{~cm}$ Spectroheliograms. - F. Mazzucconi and A. Righini / Isodensitometric Analysis of Flare on 1966, March 20. - Richard G. Teske / Soft Solar X-Rays and Solar Activity. IV: Some Evidence from the Altitude of X-Ray Source Volumes in Solar Flares. - A. F. Kuckes and R. N. Sudan / Coherent Synchrotron Deceleration and the Emission of Type II and III Solar Radio Bursts. - L. Fritzová-Švestková and Z. Švestka / Longitudinal Distribution of PCA Sources on the Sun.-- W. C. Bartley et al. / An Instrument to Measure Anisotropies of Cosmic Ray Electrons and Protons for the Explorer 34 Satellite. - F. R. Allum et al. / The Degree of Anisotropy of Cosmic Ray Electrons of Solar Origin.
\end{abstract}

\section{Research Note:}

C. Chambe and P. Lantos / Influence of Helium and Heavy Elements on the Radio Absorption Coefficient.

Abstracts of Forthcoming Papers.

Abstracts of Papers from Other Journals.

Subscription price per volume of 500 pages Dfl. 110,40 (US $\$ 30.95$ ) including postage.

Five volumes are published yearly

Personal subscription price on request

\section{REIDEL PUBLISHING COMPANY}

\author{
DORDRECHT-HOLLAND
}




\section{Information for Authors}

Astrophysics and Space Science is a journal opened primarily to original contributions from the entire domain of astrophysics and allied fields of cosmo-chemistry, dynamics, etc. - stellar, galactic and extragalactic - excluding, however, the Sun; and with emphasis on topics opened up by the methods of space research. It contains observational and theoretical papers as well as those concerned with the techniques of instrumentation (ground-based optical and radio telescopes, spectrometric equipment, as well as with the instrumentation associated with balloon, rocket, or satellite astronomy). No significant contribution will be declined because of its size or number of illustrations, as long as it can be printed in a single issue of the journal. In addition, we expect to publish from time to time invited review papers in the form of critical discussions on problems of current interest; and keep a column open for Book Reviews.

Manuscripts for publication should be submitted (in duplicate) to the Editor-in-chief or any one of the Regional Co-editors; communications received by them through members of the Editorial Board can receive more expeditious treatment. In form the MSS should be typewritten (double-spaced), with a wide left-hand margin. Any unusual symbols used should be explained by pencil-written notes. The use of italics is to be indicated by single underlining; bold-face (vectors), by wavy underlining. Please make a clear distinction between the letter ' $O$ ' and the zero symbol; or between the letter ' 1 ' and number ' 1 '. Each page of the MS should be numbered. The first page should contain the article title, author's name and affiliation. At the bottom of this page, the number of copies, of MS pages, figures, and tables should be noted. It should also contain the complete address of the author (or the person to whom proofs are to be sent). The second page should contain an Abstract, written in the language of the paper, and not exceeding in length 1 printed page. Papers written in a language other than English should have an English abstract (a translation of which can be prepared by the Editors), and the use of multi-language abstracts will be encouraged. The authors of longer papers are encouraged to organize their MSS in sections with appropriate sub-headings (e.g., 1: Introduction; 2:Observational Data or Equations of the Problem; 3: Reduction of Observations, or Solution of Equations; 4: Discussion of the Results), numbered in Arabic numerals.

Tables are to be numbered consecutively, in Roman numerals, in order of their intended appearance in the text. Each should be typed on a separate sheet, and provided with appropriate headings.

Figures and Illustrations should be submitted in such a form as to permit reproduction without retouching. Line drawings should be done in India ink; with large enough lettering to permit reduction. All figures should be provided with a caption, numbered. Photographs for reproduction as half-tones should be glossy prints; and if they contain no legend, their orientation (e.g., North-South) should be marked on their reverse side. Authors should realize the importance of good illustrations for fuller understanding of their subject.

Units. All scientific or technical data included in the text should be stated in the metric and other absolute (c.g.s.) systems. The use of the English or other regional systems of units should be avoided.

Footnotes to appear at the bottom of a page should be reduced to a minimum, and used only when essential.

References should be collected at the end of a paper, in alphabetic and chronological order. Multiauthor references (i.e., of three and more authors) in the text can be given by the name of the first author and the expression 'et al.' suffixes $a, b$, etc. following the data used to distinguish more works by the same author in the same year. References at the end of the paper should contain the name and initials of the author(s), the year of publication, suitable abbreviation of the book or journal, its volume, and pages referred to. Quotation of article titles in references is optional.

Proofs. Each author will receive two galley proofs of his article from the publisher (with an annotated copy of his MS), and is requested to return one, with the MS, with corrections, to the publisher within a week (authors may use words for explanation). In the case proofs are not returned in time, they will be read by the Editor-in-chief against the second copy of the MS, and returned for production without the author's comments. The Editor-in-chief alone will read the page-proofs to ensure that corrections marked by the authors in their galleys have been properly effected. Should authors desire to make any further corrections at this stage, please communicate direct with the Editor-in-chief rather than with the publisher.

Reprints. Authors will receive automatically 25 reprints of their articles free of charge. Additional reprints (with or without covers) can be ordered at the time of the receipt of the proofs. 


\section{CONTENTS}

W. D. HeINTZ / Colloque No. 5 de l'UAI

SESSION I

PAUl Couteau / La mesure des étoiles doubles visuelles. (Exposé Introductif) 7 W. S. FINSEN / Twenty Years of Double-Star Interferometry and its Lessons 13 OTto G. FRANz / Astrometric Application of the Photoelectric Scanning Technique 20 ERIK HøG / A Scanning Micrometer with On-Line Computer 22

R. EDWARD NATHER and DAVID S. EVANS / Discovery and Measurement of Double Stars by Lunar Occultations

\section{SESSION II}

K. Aa. STRAND / Astrometry of Double Stars. (Introductory Lecture)

Willem J. L Uyten / Double Stars with Common Proper Motion

A. N. DEUTSCH / Étoiles doubles révélées par leurs mouvements propres communs

PAUl CoUteAu / Sur la validité de la relation masse-luminosité dans le calcul des masses des étoiles

P. LAQUES / Contribution à la mesure des binaires visuelles au moyen de la camera électronique Lallemand

P. LACROUTE / Réflexions sur quelques méthodes de mesures d'étoiles doubles et leur emploi

SESSION III

J. DOMMANGET / L'observation spectroscopique des couples visuels. (Exposé Introductif)

A. H. BATTEN and J. M. FLETCHER / The Measurement of Radial-Velocity Differences

Between the Components of Close Visual Binary Systems

FREDERICK R. WEST / Spectroscopic Observations of Visual Double Stars

C. D. SCARFE / Some Spectroscopic Observations of Visual Binaries

T. S. GALKINA / Some Results of the Spectroscopic Study of Four Close Binary Systems of Early Spectral Types

\section{SESSION IV}

W. D. HEINTZ / Errors of Observation in Double-Star Work. (Abridged Version of Introductory Exposé)

J. DOMmANGET / Calcul des erreurs moyennes affectant les mesures d'étoiles doubles visuelles

J. DOMMANGET / Les erreurs affectant les périodes, les demi-grands axes et les masses totales des couples visuels orbitaux

s. AREND / Le problème des erreurs du point de vue de l'observateur et du point de vue du calculateur d'orbites

SARAH LEe LIP PINCOTT/ Systematic Errors in the Photographic Positions of Double Stars at the Sproul Observatory

SESSION $V$

P. MULLER / Photométrie des étoiles doubles. (Lecture introductive)

OTTO G. FRANZ / Photometric Observations of Visual Double Stars by the Area

Scanning Technique

K. D. RAKos / Photoelectric Observations of the Occultations of Binaries by the Moon

K. Aa. str AND / Photovisual Magnitude Differences of Double Stars

L. BINNENDIJK / The Light Variation and the Orbital Elements of AM Leonis=ADS 8024 A

P. LAQUES / Intérêt de la caméra électronique Lallemand pour la photométrie des binaires visuelles 